\title{
Effects of Phellinus spp. Extract on Alcohol Metabolic Enzymes in Alcohol-treated Rats
}

\author{
Sung-Su Kim ${ }^{\dagger}$ \\ Department of Biomedical Laboratory Science, Daejeon University, Daejeon 34520, Korea
}

\begin{abstract}
Alcoholism is a significant health problem in the world. The liver is the first and primary target organ for alcohol metabolism. Alcohol dehydrogenase and aldehyde dehydrogenase play important roles in the metabolism of alcohol and aldehyde. In this study, I aimed to investigate the eliminatory effects of a Phellinus spp. extract on alcohol metabolism in drunken Sprague-Dawley (SD) rats. Male SD rats were given Phellinus spp. extract at $30 \mathrm{~min}$ after $40 \%$ (5 g/kg) alcohol ingestion. To assay the effect of Phellinus spp. extract on blood alcohol concentration, blood samples were taken from the tail vein at 1, 3 and $5 \mathrm{~h}$ after alcohol ingestion. The concentrations of alcohol, alcohol dehydrogenase, and aldehyde dehydrogenase in Phellinus spp. extract treated rat were significantly lower than that of the control with a time-dependent manner. In addition, the alanine aminotransferase and aspartate aminotransferase activities of Phellinus spp. extract-treated groups were altered compared to those of the control group. These results suggest that Phellinus spp. extract intake can have a positive effect on the reduction of alcohol, alcohol dehydrogenase, and aldehyde dehydrogenase concentrations in the blood and may alleviate acute alcohol-induced hepatotoxicity by altering alcohol metabolic enzyme activities. Phellinus spp. extract is thus a good nutraceutical candidate.
\end{abstract}

Key Words: Alcoholism, Phellinus spp, Mushroom, Nutraceutical, Liver injury

\section{INTRODUCTION}

Alcohol is the most used and commonly abused drug. Alcohol is a mild toxicant and its toxicity primarily comes from its metabolism. Abused alcohol is the main cause of liver disease worldwide and alcoholic liver disease is high ranked among the major causes of morbidity and mortality in the world (Smathers et al., 2011). Every year, it affects millions of people. The liver is the first and primary target organ for alcohol metabolism (Lieber, 1988). But, other organs, including the kidneys, brain, and lungs, may also be affected by alcohol toxicity (Guidot and Roman, 2002).
Alcohol is primarily catalyzed into acetaldehyde by alcoholic dehydrogenase (ADH) and cytochrome P4502E1, key enzymes in the microsomal ethanol oxidizing system. Thereafter, acetaldehyde is transformed into acetic acid by mitochondrial and cytosolic acetaldehyde dehydrogenase (ALDH) isoenzymes (Klyosov et al., 1996). Mushrooms have currently received distinctive attention as physiologically functional foods and as commendable sources of natural medicine (Dai et al., 2010). Phellinus linteus (P. linteus), Phellinus gilvus (P. gilvus) and P. baumii are medicinal mushrooms belonging to the Hymenochaetaceae basidiomycetes family (Hwang et al., 2004), which is a source of many antitumor or immunostimulating polysaccharides and

\footnotetext{
* Received: June 20, 2016 / Revised: June 28, 2016 / Accepted: June 28, 2016

${ }^{\dagger}$ Corresponding author: Sung-Su Kim. Department of Biomedical Laboratory Science, Daejeon University, Daejeon 34520, Korea.

Tel: +82-42-280-2903, Fax: +82-42-280-2904, e-mail: sungsu@dju.kr

(C) The Korean Society for Biomedical Laboratory Sciences. All rights reserved.

(c) This is an Open Access article distributed under the terms of the Creative Commons Attribution Non-Commercial License (http://creativecommons.org/licenses/by-nc/3.0/) which permits unrestricted non-commercial use, distribution, and reproduction in any medium, provided the original work is properly cited.
} 
has been utilized in medicine for many human diseases in several Asian countries (including Korea) for a long time. A research regarding $P$. linteus demonstrates that it possesses antitumor (Kim et al., 2004), immunomodulating (Kim et al., 2004), antibacterial (Hur et al., 2004), antiangiogenic and antioxidant activity (Song et al., 2003). Furthermore, recent studies have shown that many other genera of Phellinus (e.g. P. baumii, $P$. gilvus and $P$. igniarius) also have potent pharmacological activities (Jang et al., 2004; Hwang et al., 2005; Lee et al., 2010). It has also been reported the anti-platelet (Kamruzzaman et al., 2011) and anti-inflammatory effects (Yayeh et al., 2012) of this mushroom extract; however, its protective effect against alcohol-induced liver diseases has never been investigated.

The aim of the current study was to investigate the protective effects of Phellinus spp. extract on alcohol-induced hepatotoxicity in rats. To determine if intake of Phellinus spp. extract caused any liver damage, serum levels of alanine aminotransferase (ALT) and aspartate aminotransferase (AST) were also determined. With AST and ALT in the blood, blood alcohol dehydrogenase (ADH) activity and aldehyde dehydrogenase (ALDH) activities were also determined to evaluate the protective effects of Phellinus spp. extract on alcohol-induced hepatotoxicity.

\section{MATERIALS AND METHODS}

\section{Preparation of Phellinus spp. extract}

All mushroom Phellinus spp. used for preparing extract were obtained from company 'Bukseorak' (Seoul, Korea). Fresh mushrooms were washed and ground with grinder to perform successive extractions. One kilogram of fresh mushroom was incubated in $5 \mathrm{~L}$ of distilled water, and filtered under high temperature/ high pressure three times. The filtrate was heated and dried to over $60 \%$ concentration using a rotary vacuum evaporator.

\section{Animals}

Male SD rats (180 200 g, 6 weeks old) were used for the study. After 1 week of adaptation, all animals were housed in a temperature $\left(25^{\circ} \mathrm{C}\right)$ and humidity $(50 \%)$ controlled room with a 12-h light/12-h dark cycle. Water and a normal stan- dard pellet diet were available ad libitum throughout the experimental period.

\section{Acute alcohol-induced liver injury in mice}

After 1 week of acclimatization, the rats were randomly allocated into 2 groups. The two groups were Group I (control group): rats received $0.2 \mathrm{~mL}$ water by gavage, and Group II (Phellinus spp. extract-treated group): the rats were treated with Phellinus spp. extract $(0.04 \mathrm{mg} / \mathrm{kg})$. After or before 30 $\mathrm{min}$, each rat received alcohol diluted in water $(40 \%, \mathrm{v} / \mathrm{v})$ at $5 \mathrm{~g} / \mathrm{kg}$. At 1, 3 and $5 \mathrm{~h}$ after the administration of alcohol, blood was collected from the tail vein to determine biochemical parameters. The rats received humane care, and experiments were performed according to the criteria outlined in the Guide for the Care and Use of Laboratory Animals and with approval of the Animal Care and Use Committee of Daejeon University (DJUARB2014-046).

\section{Serum alcohol concentration}

A blood alcohol assay kit (Abcam, USA) was used, following a slightly modified version of the manufacturer's protocol, to determine the serum alcohol concentration. Briefly, $5 \mu$ of serum was mixed with $50 \mu$ of reaction mixture. After mixing for $30 \mathrm{~min}$ at $37^{\circ} \mathrm{C}$ the absorbance was measured at a wavelength of $570 \mathrm{~nm}$. The alcohol concentration was calculated according to the equation provided with the kit

\section{Assessment of AST and ALT}

AST and ALT activities are commonly used to assess hepatic function. Serum levels of AST and ALT were assessed using an AST or an ALT Kit (Abcam, USA). Serum was diluted with phosphate buffered saline (PBS) prior to performing the assay. Yellow-colored hydrazones, which are metabolites of AST and ALT, were measured at a wavelength of $570 \mathrm{~nm}$.

\section{Assessment of ADH and ALDH}

The reaction mixtures for assay were pre-incubated with $50 \mu \mathrm{L}$ of enzyme source for $5 \mathrm{~min}$ at room temperature and the change in absorbance at $450 \mathrm{~nm}$ was monitored for 30 min to determine the amount of NADH generated. The 
A

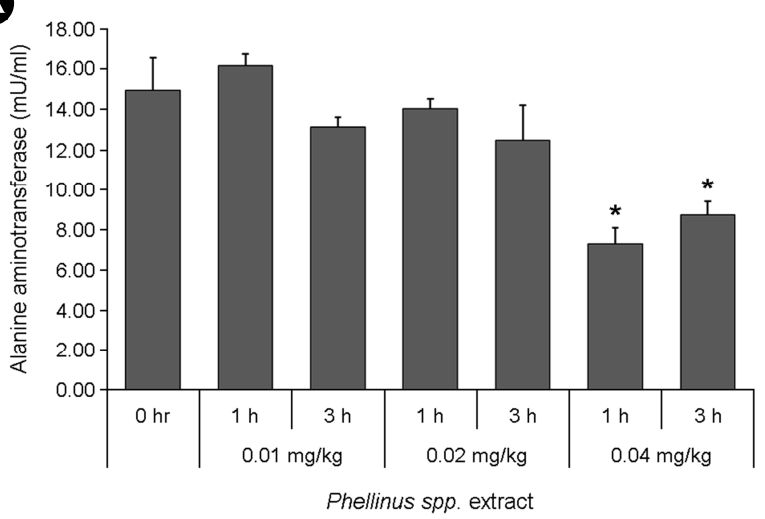

B

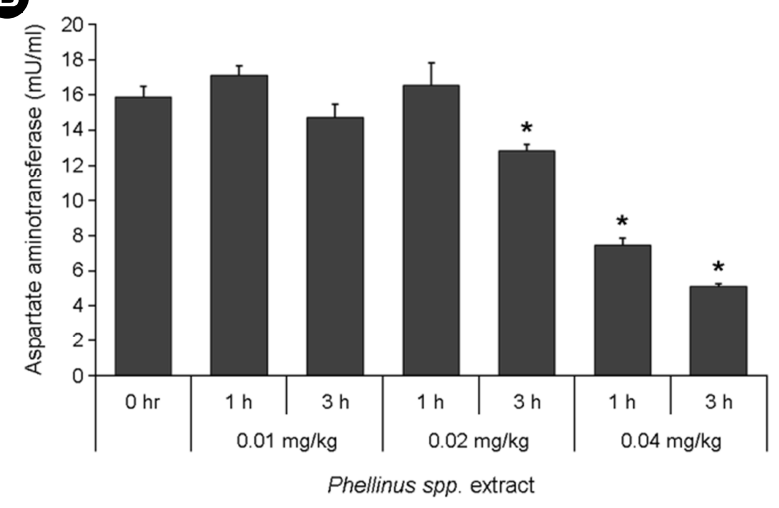

Fig. 1. Effects of Phellinus spp. extract intake on serum of (A) alanine aminotransferase (ALT) and (B) aspartate aminotransferase (AST) activities in healthy rats. At 1 and $5 \mathrm{~h}$ after the administration of Phellinus spp. extract intake, blood was collected from the tail vein. Values are shown at the mean \pm S.D. for 10 rats. Asterisks indicate significant differences between groups $(* P<0.05)$.

activities were determined by comparing the optical densities of the samples with the blank

\section{Statistical analysis}

All data are expressed as mean \pm standard deviation. Statistical analyses were performed using the software SPSS. The Student's $t$-test was used to determine the significance of differences among groups; differences were considered to be significant when $P<0.05$.

\section{RESULTS}

\section{Determination of Phellinus spp. extract concentration}

Alcohol-induced liver injury is indicated by elevated

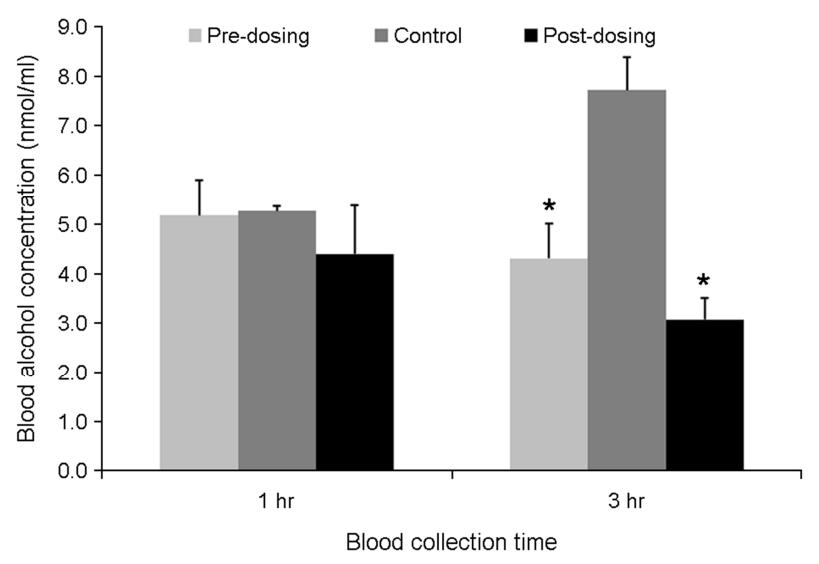

Fig. 2. Effects of Phellinus spp. extract on blood alcohol levels in pre-dosing or post-dosing rats with alcohol treatment. Values are shown at the mean \pm S.D. for 10 rats. Asterisks indicate significant differences between groups $(* P<0.05)$.

serum ALT and AST activity levels. However, some herbal medicine can also cause liver damage, which would be indicated by increases in serum AST or ALT. First, I aimed to determine whether the Phellinus spp. extract intake would cause injury to rat livers. Pre-treatment with Phellinus spp. extract make ALT (Fig. 1A) or AST (Fig. 1B) decreased as the concentration of Phellinus spp. extract and resulted in significant protection of the liver health. The Phellinus spp. extract did not induce any signs or symptoms of toxicity, and no mortality was recorded during the study.

\section{Determination of administration time of Phellinus spp. extract in serum}

Second, I want to know the administration time, predosing or post-dosing with the Phellinus spp. extract. Blood alcohol concentrations were also slightly lower in pre-dosing $(5.18 \pm 0.72 \mathrm{nmol} / \mu \mathrm{L})$ and post-dosing $(4.40 \pm 0.98 \mathrm{nmol}$ $/ \mu \mathrm{L})$ than control $(5.27 \pm 0.10 \mathrm{nmol} / \mu \mathrm{L})$ at $1 \mathrm{~h}$. At $3 \mathrm{~h}$, the blood alcohol concentration of the experimental group treated with post-dosing group was approximately 2 -fold lower than that of the negative control group, which was administered alcohol alone $(7.72 \pm 0.66 \mathrm{nmol} / \mu \mathrm{L})$. The lowest blood alcohol concentration was observed in the post-dosing group (3.07 $\pm 0.43 \mathrm{nmol} / \mu \mathrm{L})$, not pre-dosing group (4.31 $\pm 0.70 \mathrm{nmol} / \mu \mathrm{L})$ at $3 \mathrm{~h}$. (Fig. 2). Blood alcohol 


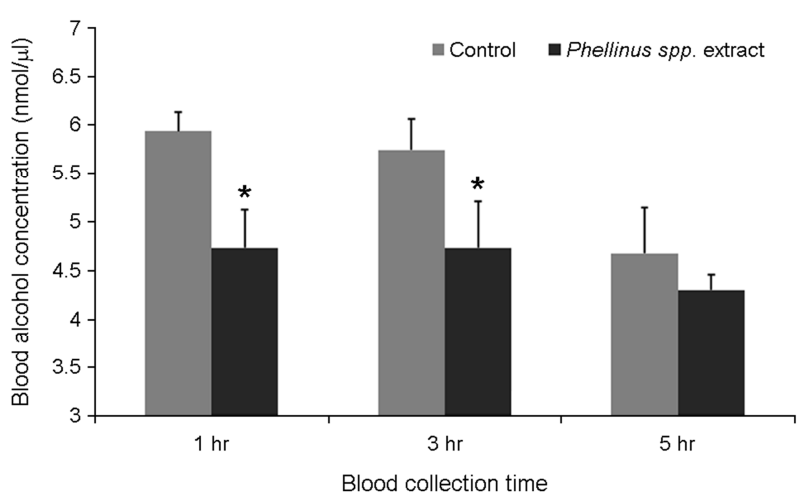

Fig. 3. Effects of Phellinus spp. extract on blood alcohol levels in drunken rats. Values are shown at the mean \pm S.D. for 10 rats. Asterisks indicate significant differences between groups $\left({ }^{*} P<0.05\right)$.

concentrations of the post-dosing groups decreased in a time-dependent manner and is post-dosing manner is better than pre-dosing.

\section{Effects of Phellinus spp. extract on blood alcohol concen- tration in serum}

Blood alcohol concentrations of Phellinus spp. extracttreated rats were measured at 1,3 and $5 \mathrm{~h}$ after administration of $40 \%$ alcohol. After alcohol exposure, blood alcohol concentrations ranged from 5.94 to $4.67 \mathrm{nmol} / \mu \mathrm{L}$ (Fig. 3). The blood alcohol concentration of the Phellinus spp. extract-treated groups $(4.73 \pm 0.38 \mathrm{nmol} / \mu \mathrm{L})$ was lower than that of the negative control group, which was administered alcohol alone $(5.94 \pm 0.19 \mathrm{nmol} / \mu \mathrm{L})$ at $1 \mathrm{~h}$. Serum alcohol concentrations were also slightly lower in Phellinus spp. extract-treated groups $(4.30 \pm 0.15 \mathrm{nmol} /$ $\mu \mathrm{L})$ than in control $(4.67 \pm 0.46 \mathrm{nmol} / \mu \mathrm{L})$ at $5 \mathrm{~h}$. Blood alcohol concentrations of the Phellinus spp. extract-treated groups decreased in a time-dependent manner. The blood alcohol concentration of the Phellinus spp. extract-treated groups at $1 \mathrm{~h}$ is almost same concentration of control at $5 \mathrm{~h}$.

\section{Effects of Phellinus spp. extract on ALT and AST activity levels}

At $1 \mathrm{~h}$, in ALT activity, there was no difference between groups treated with Phellinus spp. extract and the negative control group. However, at $3 \mathrm{~h}$, the ALT concentration was
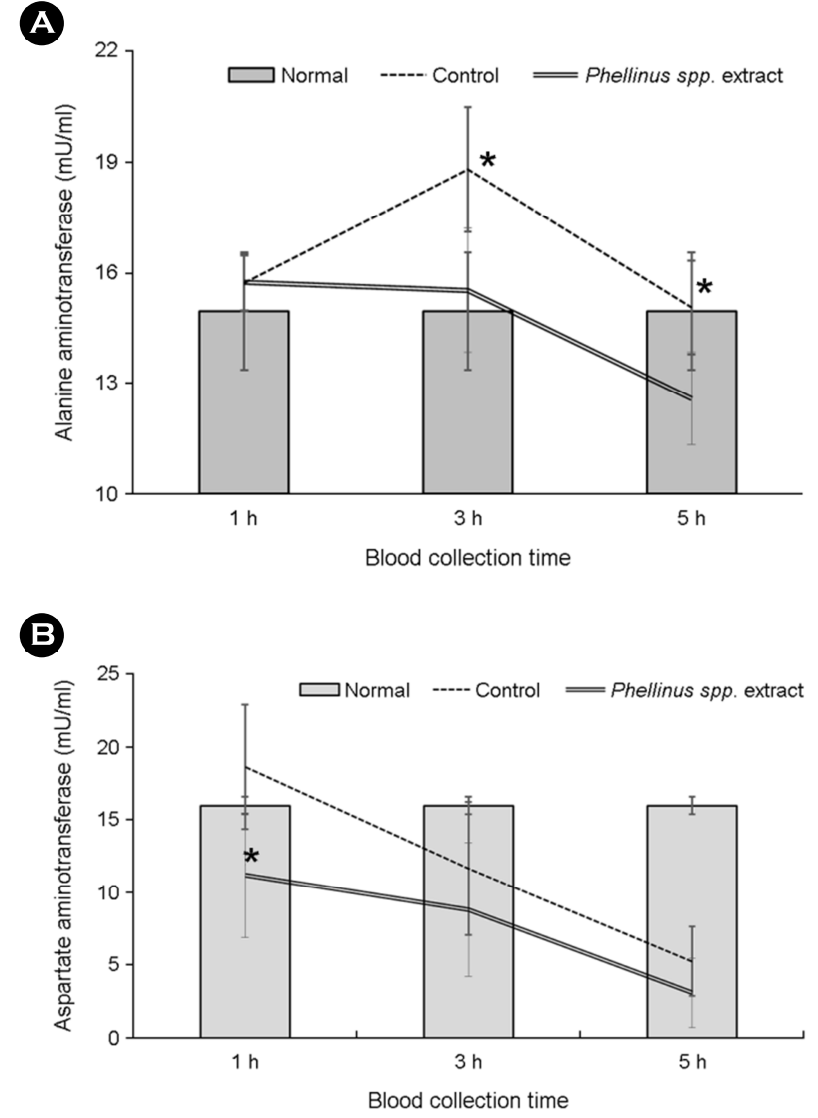

Fig. 4. Effects of Phellinus spp. extract on serum of (A) alanine aminotransferase (ALT) and (B) aspartate aminotransferase (AST) activities in drunken rats. Normal is a group without intake. Values are shown as the mean \pm S.D. for 10 rats. Asterisks indicate significant differences between groups $(* P<0.05)$.

lower in the groups treated with Phellinus spp. extract (15.54 $\pm 1.68 \mathrm{mU} / \mathrm{mL})$ than in the negative control group (18.81 $\pm 1.33 \mathrm{mU} / \mathrm{mL}$ ). The lowest serum ALT concentration was observed in the group treated with Phellinus spp. extract $(12.59 \pm 1.27 \mathrm{mU} / \mathrm{mL})$ at $5 \mathrm{~h}$ (Fig. 4A). In AST, at $1 \mathrm{~h}$, the AST concentration was lower in the groups treated with Phellinus spp. extract $(11.17 \pm 4.28 \mathrm{mU} / \mathrm{mL})$ than in the negative control group (18.61 $\pm 3.08 \mathrm{mU} / \mathrm{mL})$ (Fig. 4B).

\section{Effects of Phellinus spp. extract on ADH and ALDH} levels

At $3 \mathrm{~h}$, serum ADH concentrations were also slightly higher in groups treated with Phellinus spp. extract than in the negative control group. However, at $5 \mathrm{~h}$, the ADH con- 
A

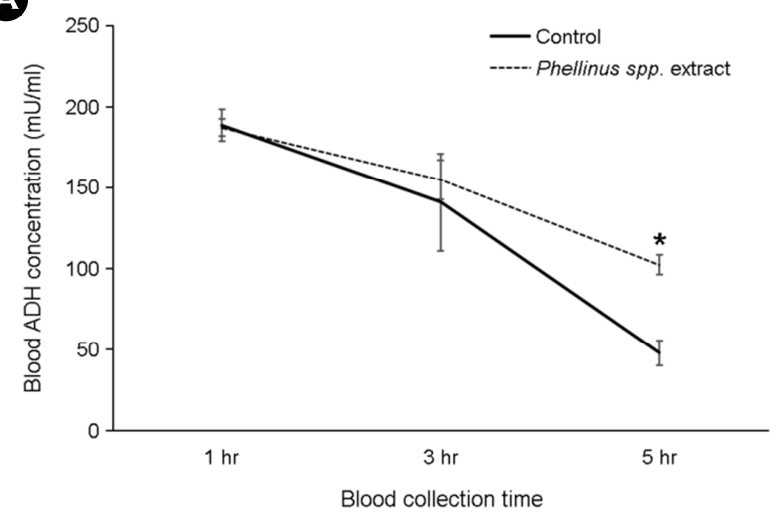

B

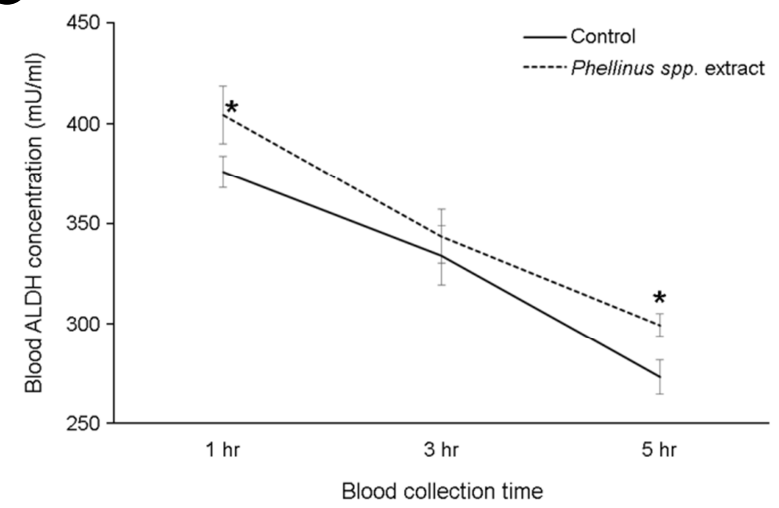

Fig. 5. Effects of Phellinus spp. extract on (A) alcohol dehydrogenase (ADH) and (B) aldehyde dehydrogenase (ALDH) activities in drunken rats. Values are shown as the mean \pm S.D. for 10 rats. Asterisks indicate significant differences between groups $\left({ }^{*} P<0.05\right)$.

centration was higher in the groups treated with Phellinus spp. extract $(102.15 \pm 6.19 \mathrm{mU} / \mathrm{mL})$ than in the negative control group $(47.57 \pm 7.61 \mathrm{mU} / \mathrm{mL})$. The highest serum ADH concentration was observed in the group treated with Phellinus spp. extract at $5 \mathrm{~h}$ (Fig. 5A). At $1 \mathrm{~h}$, the serum ALDH concentration of the Phellinus spp. extract-treated group (404.49 $\pm 14.38 \mathrm{mU} / \mathrm{mL})$ had slightly higher than that of control $(376.00 \pm 7.79 \mathrm{mU} / \mathrm{mL})$ (Fig. 5B).

\section{DISCUSSION}

In this study, I investigated the protective effects of Phellinus spp. extract on alcohol-induced liver damage in rat. Mushrooms are classified as a fungus and consist of a spore-bearing fruit body. Mushrooms are not only a nutritious food, but also are a therapeutic medicine (Zjawiony, 2004; Lee et al., 2010; Wang et al., 2014). Of the wild mushrooms studied so far, P. baumii was reported for anti-obesity (Noh et al., 2011), free radical scavenging activity (Lee et al., 2010) and hypoglycemic (Hwang et al., 2005) functions. Indeed, mushrooms produce various classes of secondary metabolites with diverse biological activities, including immunomodulatory, cardiovascular, anti-inflammatory, antidiabetic, antiviral, antioxidant, antitumor, and antimicrobial properties (Zjawiony, 2004; Lee et al., 2010; Kim et al., 2013). Due to these properties, mushrooms have been recognized as a source for the development of medicine and nutraceuticals (Kim et al., 2013).

Alcohol dependence and alcohol abuse are known to be primary causes of end-stage liver disease and substantial morbidity and mortality (Sehrawat and Sultana, 2006). Alcohol-induced injury in liver is a major complication of excessive alcohol intake that results in severely health problem to individuals and is a significant effects on social healthcare plan.

In this study, consumption of a Phellinus spp. extract was demonstrated to significantly improve serum biochemical indices and to influence alcohol metabolizing enzymes in liver. Alcohol consumption is notably associated with liver damage and a prominent sign of liver injury. The indication of Liver problems is the leakage of cellular enzymes (AST, ALT) into the serum (Sehrawat and Sultana, 2006). Phellinus spp. extract did not appear to cause liver injury (Fig. 1) and shows the potential for use as a health food and post-dosing is better than the pre-dosing to decrease blood alcohol (Fig. 2).

Alcohol-treated rats show high activity of these toxicity marker enzymes, indicating increased membrane permeability, cellular damage, and/or necrosis of hepatocytes (Baldi et al., 1993; Tahir and Sultana, 2011). Acute alcohol intake significantly increases the serum levels of AST and ALT. Compared to the alcohol-treated group, treatment with Phellinus spp. extract decreased serum ALT (Fig. 4A) and AST activity (Fig. 4B) in the present study.

Silymarin (Song et al., 2006), a Decalepis hamiltonii's root (Srivastava and Shivanandappa, 2006), and glycoproteins from Acanthopanax senticosus (Choi et al., 2006) have 
also been shown to have protective effects against alcoholinduced liver toxicity. In an acute alcohol treatment model, Phellinus spp. extract administration significantly alleviated alcohol-induced damage in livers. These results suggest that Phellinus spp. extract can be used as a healthy inducer of liver function for reducing hepatotoxicity.

Here, therefore, I report the protective effect of Phellinus spp. extract against alcohol-induced liver disease. These liver-protective effects of Phellinus spp. extract suggest that this natural product could be applicable as a nutraceutical for the prevention and control of alcohol-induced damage.

\section{Acknowledgements}

This work was supported by the RIC program of Ministry of Knowledge Economy in Daejeon University.

\section{Conflict of interest}

The researcher claims no conflicts of interest

\section{REFERENCES}

Baldi E, Burra P, Plebani M, Salvagnini M. Serum malondialdehyde and mitochondrial aspartate aminotransferase activity as markers of chronic alcohol intake and alcoholic liver disease. Ital J Gastroenterol. 1993. 258: 429-432.

Choi JS, Yoon TJ, Kang KR, Lee KH, Kim WH, Suh YH, Song J, Jung MH. Glycoprotein isolated from Acanthopanax senticosus protects against hepatotoxicity induced by acute and chronic alcohol treatment. Biol Pharm Bull. 2006. 292: 306 $-314$.

Dai YC, Zhou LW, Cui BK, Chen YQ, Decock C. Current advances in Phellinus sensu lato: medicinal species, functions, metabolites and mechanisms. Appl Microbiol Biotechnol. 2010. 875: $1587-1593$

Guidot DM, Roman J. Chronic ethanol ingestion increases susceptibility to acute lung injury: role of oxidative stress and tissue remodeling. Chest. 2002. 1226 Suppl: 309S-314S.

Hur JM, Yang CH, Han SH, Lee SH, You YO, Park JC, Kim KJ. Antibacterial effect of Phellinus linteus against methicillinresistant Staphylococcus aureus. Fitoterapia. 2004. 756: 603 -605 .

Hwang HJ, Kim SW, Lim JM, Joo JH, Kim HO, Kim HM, Yun JW. Hypoglycemic effect of crude exopolysaccharides produced by a medicinal mushroom Phellinus baumii in streptozotocininduced diabetic rats. Life Sci. 2005. 7626: 3069-3080.

Hwang HJ, Kim SW, Xu CP, Choi JW, Yun JW. Morphological and rheological properties of the three different species of basidiomycetes Phellinus in submerged cultures. J Appl Microbiol. 2004. 966: 1296-1305.

Jang BS, Kim JC, Bae JS, Rhee MH, Jang KH, Song JC, Kwon OD, Park SC. Extracts of Phellinus gilvus and Phellinus baumii inhibit pulmonary inflammation induced by lipopolysaccharide in rats. Biotechnol Lett. 2004. 261: 31-33.

Kamruzzaman SM, Endale M, Oh WJ, Park SC, Kim TH, Lee IK, Cho JY, Park HJ, Kim SK, Yun BS, Rhee MH. Antiplatelet activity of Phellinus baumii methanol extract is mediated by cyclic AMP elevation and inhibition of collagen-activated integrin-alpha(IIb) beta(3) and MAP kinase. Phytother Res. 2011. 2511: 1596-1603.

Kim GY, Oh WK, Shin BC, Shin YI, Park YC, Ahn SC, Lee JD, Bae YS, Kwak JY, Park YM. Proteoglycan isolated from Phellinus linteus inhibits tumor growth through mechanisms leading to an activation of $\mathrm{CD} 11 \mathrm{c}+\mathrm{CD} 8+\mathrm{DC}$ and type I helper T cell-dominant immune state. FEBS Lett. 2004. 5763: 391 -400 .

Kim SE, Hwang BS, Song JG, Lee SW, Lee IK, Yun BS. New bioactive compounds from korean native mushrooms. Mycobiology. 2013. 414: 171-176.

Kim SH, Song YS, Kim SK, Kim BC, Lim CJ, Park EH. Antiinflammatory and related pharmacological activities of the n-BuOH subfraction of mushroom Phellinus linteus. J Ethnopharmacol. 2004. 931: 141-146.

Klyosov AA, Rashkovetsky LG, Tahir MK, Keung WM. Possible role of liver cytosolic and mitochondrial aldehyde dehydrogenases in acetaldehyde metabolism. Biochemistry. 1996. 3514 4445-4456

Lee IK, Han MS, Lee MS, Kim YS, Yun BS. Styrylpyrones from the medicinal fungus Phellinus baumii and their antioxidant properties. Bioorg Med Chem Lett. 2010. 2018: 5459-5461.

Lieber CS. Biochemical and molecular basis of alcohol-induced injury to liver and other tissues. N Engl J Med. 1988. 31925 1639-1650.

Noh JR, Lee IK, Ly SY, Yang KJ, Gang GT, Kim YH, Hwang JH, Yun BS, Lee CH. A Phellinus baumii extract reduces obesity in high-fat diet-fed mice and absorption of triglyceride in lipid-loaded mice. J Med Food. 2011. 143: 209-218.

Sehrawat A, Sultana S. Evaluation of possible mechanisms of protective role of Tamarix gallica against DEN initiated and 
2-AAF promoted hepatocarcinogenesis in male Wistar rats. Life Sci. 2006. 7915: 1456-1465.

Smathers RL, Galligan JJ, Stewart BJ, Petersen DR. Overview of lipid peroxidation products and hepatic protein modification in alcoholic liver disease. Chem Biol Interact. 2011. 1921-2: 107-112.

Song YS, Kim SH, Sa JH, Jin C, Lim CJ, Park EH. Anti-angiogenic, antioxidant and xanthine oxidase inhibition activities of the mushroom Phellinus linteus. J Ethnopharmacol. 2003. 881: 113-116.

Song Z, Deaciuc I, Song M, Lee DY, Liu Y, Ji X, McClain C. Silymarin protects against acute ethanol-induced hepatotoxicity in mice. Alcohol Clin Exp Res. 2006. 303: 407-413.

Srivastava A, Shivanandappa T. Hepatoprotective effect of the aqueous extract of the roots of Decalepis hamiltonii against ethanol-induced oxidative stress in rats. Hepatol Res. 2006.
354: 267-275.

Tahir M, Sultana S. Chrysin modulates ethanol metabolism in Wistar rats: a promising role against organ toxicities. Alcohol Alcohol. 2011. 464: 383-392.

Wang XM, Zhang J, Wu LH, Zhao YL, Li T, Li JQ, Wang YZ, Liu HG. A mini-review of chemical composition and nutritional value of edible wild-grown mushroom from China. Food Chem. 2014. 151: 279-285.

Yayeh T, Oh WJ, Park SC, Kim TH, Cho JY, Park HJ, Lee IK, Kim SK, Hong SB, Yun BS, Rhee MH. Phellinus baumii ethyl acetate extract inhibits lipopolysaccharide-induced iNOS, COX-2, and proinflammatory cytokine expression in RAW264.7 cells. J Nat Med. 2012. 661: 49-54.

Zjawiony JK. Biologically active compounds from Aphyllophorales (polypore) fungi. J Nat Prod. 2004. 672: 300-310. 